\title{
SUBMERGED ARC WELDING A REVIEW PAPER
}

\author{
Mohd Hassan , Sanjay Kumar Jha, Vijay Pandey \\ Department of Production Engineering, \\ Birla Institute of Technology, Ranchi (Jharkhand) \\ vpandeybit@rediffmail.com
}

\begin{abstract}
-
Submerged Arc welding process is automated and semiautomated high deposition down hand welding process not vertical or over welding process, The fundamental difference of this welding process is that the Arc is not visible it is submerged into the flux. Weldment is fully submerged the heat loss is minimum and the thermal efficiency is very high up to $80-90 \%$. A constant power sources and control is required because of wire feed speed control, constant voltage power supplies, digital control which provides the precise control of welding process. submerged arc welding self wire feed mechanism is used in which the flux is supply from hopper a continuous fed electrode work piece to melt the metal into the joint area and provide additional filler metal under a blanket of granular flux. This method is suitable for butt welding and fillet welding such applications as structural members in ships, Pressure vessels, Bridge beam, Massive water pipes, Penstocks, boiler, Railroad, Automobile, Aviation and Nuclear Industries, etc. Welding parameters influence the size of the weld bead and the Heat affected zone (HAZ) differently and this is attributed to the way these parameters affect the various melting efficiencies.
\end{abstract}

Keywords - Welding parameters, weld bead geometry, heat affected zone

\section{INTRODUCTION}

Welding is a fabrication process that joint material, usually metals or thermoplastics by causing coalescence. Many different energy sources are used for welding including a gas flame, an electron beam, an electric arc, laser beam, fabrication and ultrasonic frequency. Submerged arc welding is an arc welding process in which the arc is concealed by a blanket of granular and fusible flux. Flux is the main gradient in which the stability of arc depends [1]. This method is suitable for butt welding and fillet welding such applications as structural members in ships, Pressure vessels, Bridge beam, Massive water pipes, Penstocks, boiler, Railroad, Automobile, Aviation and Nuclear Industries, etc.

The high welding current used in the SAW process results in high heat input in the Weldment the consequence of this is the deterioration of the mechanical properties of the parent metal. Two main factors are responsible for this deterioration. The first comes from the welding thermal cycles which result in large HAZ within which the microstructure of the parent metal Welding parameters influence the size of the weld bead and the HAZ differently and this is attributed to the way these parameters affect the various melting efficiencies. The HAZ is an undesirable but unavoidable region in a fusion weld joint because of the heat transfer from the weld metal to the parent metal. To a certain extent, the HAZ size reflects on the grain coarsening and toughness [6]. Poor toughness can result from the large grains in a large/wide HAZ. On the other hand, a narrow HAZ indicates a steep thermal gradient and thus a fast cooling rate and a short soaking time as well as fine grain size and high toughness [7]. The effect of welding process variables on electrode melting and plate melting efficiencies of submerged arc welding has been variously studied and it was found that, there is an increase in the plate melting efficiency (PME) with increasing welding current and voltage [8]. On the basis of the work of Niles and Jackson [9], [10] derived parameters for quantifying weld melting efficiency. In the analysis, the percentage of energy consumed in melting the electrode is called the electrode melting efficiency (EME), whereas that consumed in melting the base metal is called the PME. The sum of these two efficiencies is termed the welding process melting efficiency (WPME) [11].

In submerged arc welding the quality of welding, deposit is determined by following parameters [12].

- Welding current

- Welding arc voltage

- Electrode stick out

- Grade of wire

- Travel speed

- Types of flux

- Size of electrode

- Flux layer depth

- polarity

SAW involves many metallurgical phenomena, such as melting, freezing, transformations, thermal strains, shrinkage stresses. The metallurgy of SAW is complex and depends on the compositions of the parent metal, the filler rod, and the flux, as well as on the welding parameters such as polarity, heat input, number of passes, etc [13].

Three main zones of a typical Weldment namely: [14]

(i) The parent metal (PM),

(ii) The heat affected zone (HAZ) and

(iii) The weld metal (WM) or fusion zone (FZ).

The microstructure of the weld metal is mainly coarse columnar gains, due to the relatively high heat input, large weld pool and fast solidification. Low toughness and hydrogen cracking of the weld metal results from the columnar microstructure in the weld metal. The large grains in the CGHAZ near the weld interface result in high strength and low toughness in this region. Good mechanical properties are obtained from the FGHAZ due to its very small grain size. The microstructure of the parent metal remains unchanged. The greatest advantage of SAW is its high welding productivity due to its high deposition rate, ease of automation and low 


\section{Asia Pacific Journals}

operator skill requirements [15]. Its productivity level is about 4 to 10 times that of the SMAW process. Since the electric arc is covered by the granular flux or molten slag, minimal welding fume or arc light is emitted. Therefore, the working environment is very comfortable to operators who may not need to wear goggles and thick clothes to protect themselves [16].

The physical and mechanical properties of weld metal varies with different parameters such as, weld bed geometry, current, voltage, speed, heat input filler material, flux chemistry, and pre heat temperatures[17]. Different defects were also found in welding, surface defects found in weld joint include surface porosity, misalignment, crater holes and solidification cracks, the use of unsuitable or improper welding parameter also caused defects in the weld. Compare to surface defects internal defects are more potential dangers, more difficult to find out and difficult to be inspected. Internal defects that occur in the weld joint include lack of penetration; fusions, hydrogen cracks and reheat cracks [18].

This study has identified some important issues for establishing the gap in literature namely; as shown in table-1

A- Definition of submerged arc welding (SAW).

B- Types of material used for of submerged arc welding (SAW) process.

C- Types of electrode used for of submerged arc welding (SAW) process.

D- Types of wires used for of submerged arc welding (single or double).

E- Types of power sources used for of submerged arc welding (AC or DC sources).

F- Chemical composition of material used for of submerged arc welding (SAW).

G- Chemical composition of Electrode used in submerged arc welding.

H- Types of flux used in submerged arc welding

I- Different welding parameters used in submerged arc welding.

J- Combined effect of flux and welding parameters on chemical composition of submerged arc weld metal.

K- Mechanical properties of submerged arc welding.

L- Morphology of welding joint.

M- Analysis of detailed microstructure of submerged arc welding.

N- Analysis of Heat Affected Zone (HAZ).

O- Effect of Heat input on increasing.

P- Effect of Heat input on decreasing.

Q- Applications of submerged arc welding.

R- Adaptation of submerged arc welding.
S- The Impact of submerged arc welding on the environment.

T- Theoretical research in submerged arc welding involving conceptualizing and then Defining.

U- Empirical research involving hypothesis testing.

V- A Case study of submerged arc welding.

\section{CRITICAL APPRAISAL}

- Many researchers have attempted to define the various parameters in temperature distribution in submerged arc welding.[1,22,23,24] However it seems on the techniques to predict the distortion and shrinkage are identified, and then the problem can be controlled accordingly.

- Many researchers in their experimental analysis the microstructure variations and mechanical behavior of submerge arc Characterization of welding arc and weld pool formation in vacuum gas hollow tungsten arc welding. [3,12,25,21][Application of Abel inversion in real-time calculations for circularly and elliptically symmetric radiation sources. Measurement Science and Technology 16 (3), 878884)]. However, they find the various types microstructures such as, acicular ferrite, coarse granular ferrite, and fine polygonal ferrite, and also find that welding thermal cycle and its unique feature.

- Few researchers also work on the assessment of heat affected zone (HAZ) of SAW and process through digital image [3,4,27,28] This process of arc welding provides a pure and cleaner high volume Weldment

- Some researchers work on chemical and structural characteristics of the crystalline phase in agglomerated flux for submerged arc welding $[1,2$, 27, 28]. While comprise the initial composition of flux and weight percentage of component it seems that the oxide increased at the same proportion as they were present in the original mixture.

- Many researchers have attempt to find the combined effects of flux and welding parameters on chemical composition, [3,5,23]

- Researchers find the effect of heat input on weld bead geometry of submerged arc welding [1, 3, 24, 22, and 11]. It seems that melting efficiency increased with welding current but decrease with welding speed. The bead width to depth ratio and percent dilution remained practically unchanged as heat input increased.

Notes; Viewed from the perspectives of these gaps, it is therefore, important to go on with additional research on the parameters and the morphology of submerged arc welding. 


\section{Asia Pacific Journals}

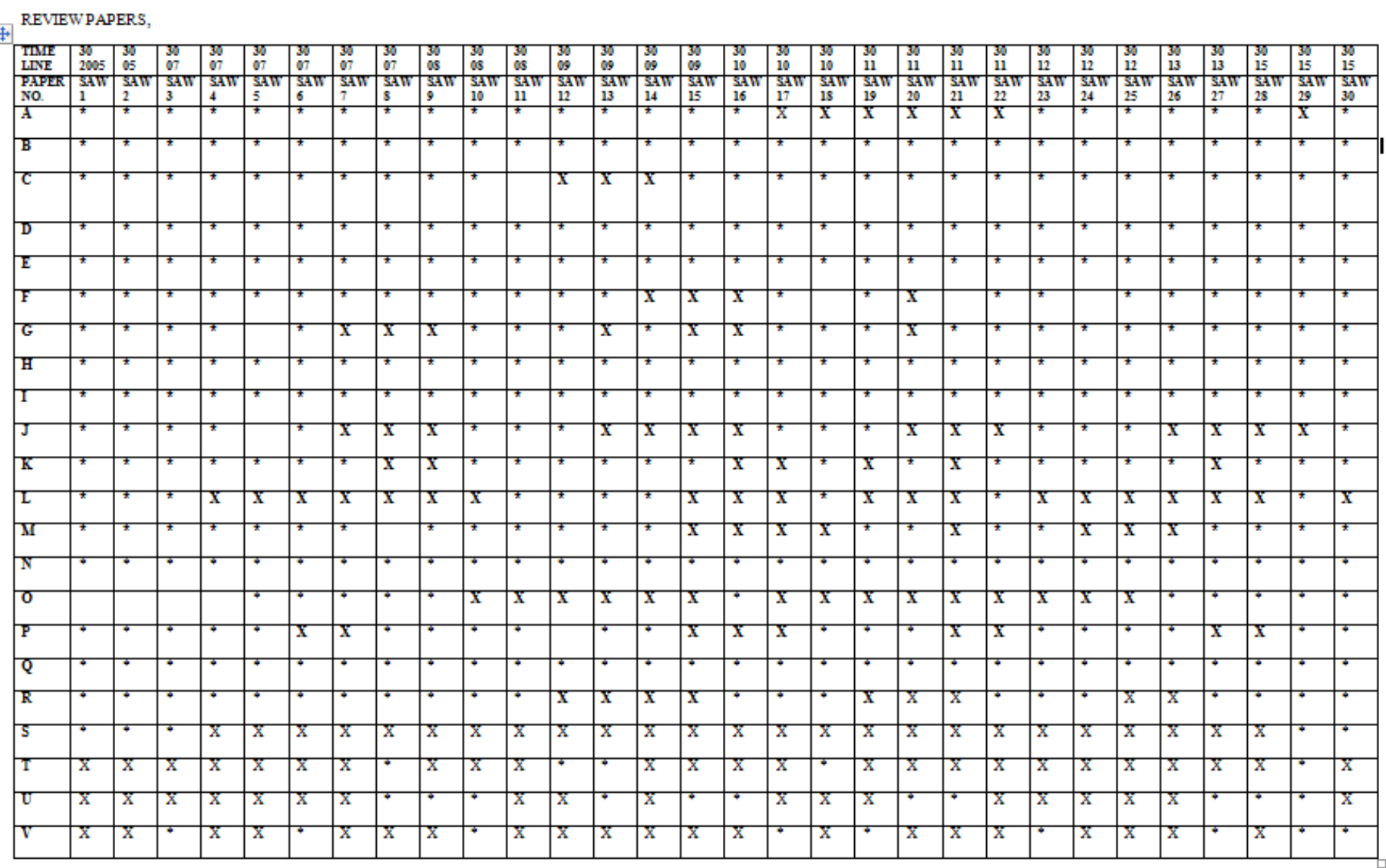

Table-1

\section{PAPER REVIEWD}

Combined effect of flux and welding parameters on chemical composition. The purpose of this investigation is to identify the relative influence of flux and welding parameters as well as their interactions on the weld metal chemistry and mechanical properties. [3].

$>$ No gaps, maximal root face in a joint with a minimal Angle are favourable taking into consideration consumption of filler metal but it can reduce quality of joint. $[15,16]$.

$>$ If surfacing is carried out with pre heating or over large areas and in several layers, the temperature of the deposited components may exceed $400^{\circ} \mathrm{c}$, and this may complicated the removal of the slag skin and reduced the quality and productivity of surfacing. $[12,13]$.

In this research the heat input was changed by changing the area travel speed while keeping the current and voltages constant. Thus higher heat input was obtained by showing down the welding speed. This means that a large amount of heat input per unit length resulted in a larger molten pool which consequently remained liquid for a longer time causing more heat to flow out to the plate and promoting a larger HAZ and larger grains. [8]

$>$ The resistance heating of the slag would be affected by the magnitude of the current flowing through it and the electrical resistance of the slag. Thus, it can be concluded that the amount of flux consumption should be dependent upon the welding parameters. $[8,9,10]$.

$>$ By controlling the parameters which determine the wave form it is possible to achieve outstanding results in terms of productivity, bead shape and penetration, heat input and reduction of distortions. $[19,20,28]$.

$>$ Heat input affects the grain structure of weld metal and HAZ. However increase in heat input from 3 to $6.3 \mathrm{KJ} / \mathrm{mm}$ does not show any systematic and pearlite in the weld metal. $[6,7,13]$.

$>$ The temperature histories obtained by four-electrode SAW Experiment were a good match with the calculation results from M1LH sources, in which the total heat input from 4 heat sources is replaced by a single heat sources, and instantaneous PH sources, in 
Asia Pacific Journals

which no consideration is taken of movement of heat sources. [7, 1, 3].

$>$ If hardness value are compared with those of resilience obtained by charpy tests, as a function of the FL distance. It is reduced that the inflection point of greatest hardness, correspond to least resilience and vice versa.

$>$ The problem of formation of the longitudinal hot cracks at the end of the welded joints is important not only in shipbuilding but also in welding pipes, 8 large vessels and in other cases in which it is necessary to weld elongated sheets whose length is several times greater than their width.[23, 24].

$>$ The WM microstructure has predominantly acicular ferrite after subjected to multi-pass submerged arc welding process. While the HAZ microstructure changes from coarse lath/ granular bainite to fine polygonal ferrite then to a mixture of original lath bainite and newly formed martensite with the distance far away from the fusion line. [3, 1, 5].

\section{CONCLUSIONS}

- Welding speed influences weld metal carbon content through oxidation reaction.

- The increase of the welding heat input in SAW size of welding imperfections with regard to the quality and length of imperfection. Increasing welding heat input improves the weld shape coefficient and decreases the possibility of creating cracks.

- The temperature of slag skin and of the deposited bead was measured with a contact thermocouple. Control of the temperature made if possible to estimate the temperature of the specimen at which the slag skin was separated.

- The influence of the welding parameters on the size of HAZ size to bead size ratio can be explained in terms of their effects on the various melting efficiencies.

- An increase in arc voltage and electrode extension also increases the flux consumption. Compared to straight polarity, the consumption is lower reverse polarity is used.

- The increase in the heat input lowered both UTS and YS of steel investigated while \% elongation increased.

\section{References}

[1] N.Murugan and V.Gunaraj. Materials Processing Technology, V.168, N.3, 2005.

[2] Ana Ma. Paniagua-Mercado, Paulino Estrada-Diaz, Victor M. López-Hirata 2003.

[3] P. Kanjilal, T.K. Pal, S.K. Majumdar, the combined effects of flux and welding parameters on chemical composition ; J. of Materials Processing Technology V.171, N.2,2006,pp. 125)

[4] S. Shen, I.N.A. Oguocha, S. Yanna copoulos, effect of heat input on weld bead geometry of submerged arc welding 2011)

[5] S. D. Bhole, J. B. Nemade, L. Collins and C. Liu, "Effect of Nickel and Molybdenum Additions on Weld Metal Toughness in a Submerged Arc Welding HSLA Line-pipe Steel",, ( Journal of Materials Process Technology, 2006, Vol. 173, pp. 92-100)
[6] Moarrefzadeh, "Choosing Suitable Shielding Gas for Thermal Optimization of GTAW Process", IREME Journal, Sep 2010.

[7] J Edwin Raja Dhas. Department of Automobile Engineering. Noorul Islam University, Nagercoil629180, India.

[8] R.S Chandel, Cooling characteristics of bead-on plate welds. Met Constr. (March), 178R-183, 1990

[9] J. R. Davis, "Alloying: Understanding the Basics", Materials Park, OH, ASM International, 2001, pp. 193-209.

[10] S.Benyounis, K.Y Olabi, Microstructural variations in a highstrength structural steel weld under isoheat input conditions of Weld. (November) 248-S-239-2008).

[11] M. Menaka, M.Vasudevan, B.Venkatraman, B. Raj: NonDestructive Testing and Condition Monitoring, V.47, N. 9, pp 9498, 2005.

[12] D.L. Olson, Effects of welding flux additions on 4340 steel weld metal composition, Welding J. (3) (1990) 115-122.

[13] Ryabtsev, the removal of the slag skin and reduced the quality and productivity of surfacing, E.O. Paton Electric Welding Institute, Kiev, Russia 2008.

[14] SUI Shao-hua, CAI Wei-wei, LIU Zhi-qiang, SONG Tian-ge, ZHANG, JOURNAL OF IRON AND STEEL RESEARCH, INTERNATIONAL. 2006, 13(2) : 65-68

[15] Jerzy Nowacki, Paweł Rybicki, Journal of Materials Processing Technology 164-165 (2005) 1082-1088

[16] C. S. Lee , R. S. Chandel \& H. P. Seow Materials and Manufacturing Processes, VoL 15, No.5, 649-666, 2000

[17] E L Makarov, H Herold, M Schtraitenberg \& A Pshennikov Welding International 200014 (4) 305-309

[18] Tomasz Kozak Welding International, 2015 Vol. 29, No. 8, 614618

[19] Liangyun Lan n, Chunlin Qiu, DewenZhao, XiuhuaGao, LinxiuD, P.L. Harrison, R.A. Farrar, Int. Mater. Rev34 (1989) 35-51

[20] K. Poorhaydari, B.M. Patchett, D.G. Ivey, Mater. Sci. Eng. A 430 436 (2006) 371-382].

[21] C.L. Davis, J.E. King, Metall. Mater. Trans. A 25A (1994) 563 573].

[22] Cho, D.W., Na, S.J., Cho, M.H., Lee, J.S. 2013a. Simulations of weld pool dynamics in V-groove GTA and GMA welding. Welding in the World 57, 223-233.

[23] Kanjilal, Majumdar, S.K Pal, T.K., Prediction of submerged arc weld-metal composition from flux ingredients with the help of statistical design of mixture experiment; Scandinavian J. of Metallurgy, V. 33, N. 3, 2004)

[24] N. Murugan and V.Gunaraj. Materials Processing Technology, V.168, N.3, 2005

[25] M. Menaka, M.Vasudevan, B.Venkatraman, B. Raj: NonDestructive Testing and Condition Monitoring, V.47, N. 9, 2005

[26] J.E. Indacochea, M. Blander, S. Shah, Submerged-arc welding: evidence for electrochemical effects on the weld pool. Weld. J. Suppl. Res. 68 (3) (1989) 77-79

[27] A.K., Dutta,G.L., Three-dimensional Finite Element Analysis to predict the different zones of Microstructure in Submerged Arc Welding; Proc., Institution of Mechanical Engineers, part B, J. of Engineering Manufacture, V.218, N. 3 2004)],

[28] C.E. Jackson, Submerged-arc welding, fluxes and relations among process variables, in: Metals Hand Book, ASM, Metals Park, OH, 1982, pp. 73-77

[29] Benyounis, K.Y, Olabi, A.G Microstructural variations in a highstrength structural steel weld under isoheat input conditions. Weld. Res. (November), 248-S-239-S. 2008

[30] B., Raman, ASM International, Metals Park, OH, USA. Basu,., 2002 